\title{
A quarta dimensão no trabalho de Trinh T. Minh- ha: desafios para a antropologia ou aprendendo a falar perto
}

\author{
JeSSIE SkLAIR
}

\begin{abstract}
resumo Este artigo trata dos desafios que o trabalho da cineasta e teórica pós-colonial feminista Trinh T. Minh-ha traz para a antropologia visual e para o projeto antropológico em uma escala mais ampla. $\mathrm{O}$ trabalho de Trinh reflete tendências em desenvolvimento na antropologia, especialmente no campo do visual, no que tange à crítica póscolonial e ao crescente interesse por novos métodos de produção de conhecimento que rejeitam a racionalidade cerebral da teoria antropológica ocidental anterior em favor de meios mais corporais, individuais e sensoriais de se entender a experiência humana. Argumento que a natureza radical da crítica de Trinh e o fato de encontrar-se fora dos limites da antropologia acadêmica geram, no seu trabalho, avanços que transcendem os esforços similares, mas limitados, atualmente em curso na disciplina. Nesse artigo investiga-se, primeiro, a interface entre o trabalho de Trinh e as referidas tendências da antropologia visual contemporânea; em seguida, passa-se a olhar mais de perto os resultados de sua prática experimental em um trabalho específico, The Fourth Dimension (A Quarta Dimensão), o seu penúltimo filme, produzido em 2001.
\end{abstract}

palavras-chave Antropologia visual. Crítica pós-colonial. Filme experimental.

Um amigo japonês disse-me que o famoso santuário imperial em Ise se mantém inalterado desde o século VII - idêntico ao que era quando foi construído pela primeira vez. Para os ocidentais, é claro, ele não parece assim tão velho. É que, segundo a tradição corrente, os edifícios em Ise têm sido reconstruídos (em locais alternados) a cada vinte anos, exatamente da mesma maneira
- usando-se os mesmos instrumentos antigos e os mesmos materiais -, e cada passo do processo é marcado pelos rituais antigos apropriados. Mas é óbvio que os instrumentos não poderiam ser exatamente os mesmos, poderiam? Eles náo teriam durado treze séculos. E o que significa dizer que os materiais são os mesmos, visto que a cada vez se usa madeira nova? E de que modo duas performances rituais poderiam jamais ser "a mesma"?

(Marshall Sahlins, Esperando Foucault, ainda, [1993] 2004: 13)

Ao longo dos últimos vinte anos o projeto antropológico tem enfrentado uma série de desafios vindos de fora e de dentro das suas fronteiras acadêmicas. No fundo desses desafios encontra-se um questionamento da própria raison d'être da disciplina, à possibilidade da produção de conhecimento legítimo sobre a cultura (seja a dos "outros" ou do próprio antropólogo), acompanhado por uma preocupação não menos complexa sobre o que seria efetivamente esse ente enigmático e elusivo sobre o qual os antropólogos escrevem já há tanto tempo e com tanta confiança. Grande parte dessas críticas vem de três áreas, a crítica feminista, a crítica literária ligada à teoria cultural e a antropologia visual. Tem sido característica dessas correntes antropológicas buscar inspiração e dialogar com trabalhos desenvolvidos fora da disciplina, numa tentativa de trazer novos desafios e possibilidades para o projeto antropológico na sua passagem para o novo século. Pretendo nesse ensaio enfocar um desses 
trabalhos, o da cineasta Trinh T. Minh-ha ${ }^{1}$, que apresenta críticas ferozes e deslocadoras do projeto antropológico, assim como possibilidades igualmente radicais para o seu futuro. Desenvolvo abaixo uma possível leitura do trabalho de Trinh, explorando, primeiro, a sua crítica à produção de conhecimento ocidental/masculino sobre "o outro" e, segundo, as alternativas por ela apresentadas em relaçáo a algumas correntes de pensamento em antropologia ao longo do último meio século. Em seguida abordo um trabalho específico, The Fourth Dimension, o penúltimo filme de Trinh, produzido em 2001.

No entanto, o primeiro deslocamento exigido por Trinh já subverte o primeiro parágrafo acima. Para Trinh, a prática de "falar sobre" (speak about) vem carregada de profundas camadas de pressupostos, implicaçóes e jogos/demonstrações de poder: "o 'falar sobre' somente compartilha da conservação de sistemas de oposiçáo binária (sujeito/objeto; Eu/Ele; Nós/Eles) de que depende o conhecimento territorializado ... assegurando uma posição de dominação para aquele que fala" (Trinh 1991: 12) ${ }^{2}$. Evitar a reprodução das relaçóes de poder epistemológicas, ela argumenta, implica abrir mão da tradição antropológica de falar sobre, e passar a "falar perto" (speak nearby). Tentando, então, considerar a proposta de Trinh com seriedade, pretendo nesse ensaio falar do trabalho perto dela e pensar (também de perto) as implicaçóes do mesmo para um projeto acadêmico que se encontra no meio de um sério e incerto processo de reavaliação e mudança.

Nesse ambiente de incerteza, um dos aspetos mais fascinantes do trabalho de Trinh é

1. Trinh, que nasceu no Vietnã e se formou originalmente em composição musical, é atualmente cineasta e teórica pós-colonial feminista, atuando como professora nos Departamentos de Retórica e de Estudos de Gênero da Universidade de Califórnia, Berkeley.

2. A tradução das citaçóes de trabalhos não disponíveis em português que aparecem ao longo do texto, é de minha autoria. a sua subversão da busca de soluçóes finais e caminhos fixos. Liberto dos limites implícitos nessa busca, aquele que falar perto das relaçóes, processos e experiências "culturais" abre-se para uma multiplicidade de direçóes e possibilidades novas para a aprendizagem da experiência humana. Portanto, a leitura do trabalho de Trinh desenvolvida abaixo não se faz como uma tentativa de apresentar uma leitura coerente e totalizada, mas como algumas reflexóes acerca de um conjunto de trabalhos que chamaram a atenção de uma jovem antropóloga preocupada tanto em entender as raízes da visão de mundo antropológica que lhe foi passada durante a sua formação, quanto em questionar essa visão conforme começa a desenvolver sua própria pesquisa.

\section{Falar Sobre}

O incomum.

Primeiro, criar necessidades; depois, ajudar

Etnólogos manuseiam a câmera da mesma foram que manuseiam as palavras

Recuperado colecionado preservado

Os Bamun os Bassari os Bobo

Como se chama mesmo o seu povo? um etnólogo pergunta a um colega

(extrato do roteiro de Reassemblage, Trinh T. Minh-ha 1982)

Exaltam o conceito de descolonização e trazem continuamente para o seu universo "o desafio do Terceiro Mundo.” Porém, não parecem perceber a diferença, mesmo quando se defrontam com ela - uma diferença que não se anuncia, que não antecipam e que não conseguem encaixar em nenhum dos diversos compartimentos de seu mundo catalogado; uma diferença que insistem em medir com réguas inadequadas, projetadas de acordo com seus mórbidos fins.

(When the Moon Waxes Red, Trinh T. Minh-ha 1991: 16). 
No cerne de todo o trabalho de Trinh, tanto escrito quanto visual, encontra-se uma crítica profunda ao poderoso discurso ocidental dominante na antropologia desde seu começo. Trinh vê esse discurso - caracterizado por uma visáo do mundo baseada em princípios masculinos, ocidentais e colonialistas/imperialistas - não somente na antropologia, mas na produção de conhecimento e no exercício do poder por parte de missionários, colonialistas e organizaçóes assistencialistas ao longo de suas histórias e nas fundaçóes do próprio pensamento intelectual ocidental. Elementos centrais desse discurso incluem a busca pela verdade, consagrada por sua natureza "científica", o caráter totalizante e onipotente dessa suposta verdade, o direito auto-concedido de representar ou falar no lugar do outro não-ocidental e - e neste último elemento Trinh direciona a sua crítica mais especificamente à antropologia - a crença de que as "culturas tradicionais" existem numa condição prístina, sendo assim ameaçadas por seu contato com o ocidente e necessitando de "recuperação, coleta e preservação" (Trinh 1982).

Em relação a isso, as primeiras experiências em antropologia visual e com o filme etnográfico tiveram uma parcela considerável de culpa, sendo a mídia visual na antropologia originalmente entendida exatamente nesse veio, como instrumento para coleta e registro de dados culturais considerados em risco de desaparecimento ${ }^{3}$. A estética por muito tempo dominante na produção do filme etnográfico refletia essa preocupação, fundada na busca de uma representação "verdadeira" e "científica" da vida cultural dos outros.

3. Essa visão do papel do visual na antropologia foi defendida com intensidade por, entre outros, Margaret Mead. Para Mead, o registro visual era uma ferramenta essencial para o projeto antropológico, sendo que: "a antropologia ... aceitou, tanto implícita quanto explicitamente, a responsabilidade de fazer e preservar os registros dos costumes e seres humanos que estáo em processo de desaparecimento" (Mead [1975] 1995 :3).
Técnicas como planos longos montados no filme sem cortes, a negação da presença do cineasta no ato de filmagem, o comentário autoritário do antropólogo em off, explicando as atividades do filme, e a preocupação em evitar montagens "artísticas" que poderiam prejudicar o caráter científico do filme, foram aplicadas com esse fim. A chegada de novas tecnologias, permitindo a gravação de som sincronizado e a entrevista, serviu em muitos casos para fortalecer essa estética, permitindo uma aproximação maior à "realidade" do momento da filmagem. Listas de critério especificaram as medidas necessárias para que os filmes fossem legitimamente "etnográficos" Ocupava um lugar central nesse critério a legitimidade científica do antropólogo-cineasta, que tinha que comprovar sua autoridade para falar do assunto/povo/cultura em questáo mostrando sua permanência estendida no local de pesquisa e às vezes produzindo informação textual para acompanhar e explicar o filme.

É essa estética e os pressupostos subjacentes a ela que é alvo da crítica do primeiro filme de Trinh, Reassemblage, de 1982. Neste, Trinh desafia as convençóes do filme etnográfico explicitadas acima com uma montagem de diversas imagens do Senegal, que fazem referência a uma abordagem convencional, mas imediatamente a subverte com a ausência de explicaçóes autoritárias.

4. Karl Heider, por exemplo, oferece uma série desses critérios no seu livro Ethnographic Film de 1976: "primeiro, a etnografia é um modo de se fazer uma descrição detalhada e uma análise do comportamento humano baseada em um estudo observacional de longa duração in loco... outra característica essencial da etnografia é que esta relaciona comportamentos específicos observados a normas culturais ... um terceiro princípio básico da etnografia é o holismo ... deve-se ter em mente que o princípio holístico serve como um princípio corretivo para tornar os filmes mais etnográficos ... para poder julgar a etnograficidade de um filme precisamos saber quanto e em até que grau a realidade foi distorcida. E ao fazermos filmes etnográficos podemos pedir que as distorçôes sejam mantidos em um nível mínimo” (Heider 1976: 6-7). 
Em seu lugar Trinh oferece um comentário fragmentado e uma trilha sonora diversificada que, junto com o uso da repetiçáo e cortes e planos não lineares, deixam clara a natureza construída de qualquer estética cinematográfica.

A antropologia visual das últimas décadas, porém, tem avançado além da estética que Trinh critica nesse filme, em grande parte na medida em que a disciplina como um todo começou a repensar seu próprio projeto. Assim sendo, parece que, em Reassemblage, Trinh questiona um modelo de filme etnográfico que precede as inovaçóes e desafios há muito tempo introduzidos na área, em uma tradição que começou com o trabalho de cineastas-antropólogos como Jean Rouch e David e Judith MacDougall, os quais enfrentaram e subverteram muitos dos pressupostos da antropologia visual já nos anos 1960 e 1970.

Jean Rouch desenvolveu a maior parte do seu trabalho cinematográfico na África Ocidental na época da independência dos países da regiáo. $\mathrm{O}$ ambiente revolucionário e experimental deste momento teve grande impacto no seu trabalho, que rompeu com as limitaçóes acadêmicas e teóricas da sua formação na Sorbonne dos anos 50, desafiando os limites da antropologia e do cinema da sua época. Para Rouch, a rígida distinção entre arte e ciência que restringia o papel da câmera na antropologia a um mecanismo de registro de dados etnográficos desintegrou-se em um trabalho que situou a busca de uma nova teoria antropológica na própria prática cinematográfica. Em razáo da resistência ao seu trabalho por parte da academia da época, Rouch foi, durante muito tempo, melhor conhecido pelos cineastas do que pelos antropólogos, situação esta que começa a ser retificada só nos últimos anos ${ }^{5}$.

Um outro elemento central no trabalho de Rouch foi a busca de uma "antropologia compartilhada" em que a câmera serviu para apro-

5. Para um tratamento mais aprofundado do trabalho de Rouch, vide Sztutman 2004 e Grimshaw 2001. ximar o trabalho do antropólogo ao mundo dos seus sujeitos, tanto na produção de trabalhos cinematográficos quanto na sua exibição. Para Rouch, tratava-se de um projeto de "democratização do saber", implicando na participação ativa dos sujeitos dos seus filmes na sua concepção, produção e análise. Essa característica do trabalho de Rouch foi compartilhada pelo casal de cineastas-antropólogos David e Judith MacDougall, especialmente nos filmes produzidos por eles na comunidade aborígine australiana no final dos anos 70 (vide Grimshaw 2001: 140-148). A produção cinematográfica e escrita desse casal também significa um projeto de grande experimentação no desenvolvimento da antropologia visual ao longo das últimas quatro décadas. Por que, então, Trinh T. Minh-ha parece dar tão pouca atenção a essas correntes inovadoras que já caracterizavam a antropologia visual do último meio século, e que à primeira vista parecem já atender às demandas da sua crítica?

A mesma dúvida pode ser articulada em relação às tendências da antropologia de maneira mais geral na época em que Trinh começou a desenvolver essa crítica. Pós-modernistas como James Clifford e George Marcus, por exemplo, desenvolveram novas abordagens nos anos oitenta, com base na crítica da produçáo do texto etnográfico na antropologia, influenciada pela crítica literária. Em trabalhos como aqueles que fazem parte da influente coletânea Writing Culture (fruto de um seminário de 1984 sobre "the making of ethnographic texts" [a confecção de textos etnográficos]), esses autores exploraram relações de poder implícitas no encontro entre o antropólogo e seu sujeito, a natureza mitológica da representação do outro 'inocente' e sem contexto histórico-político e a voz autoritária e onipotente subjacente ao texto etnográfico clássico (ver, por exemplo, Pratt 1986 e Rosaldo 1986).

Esses autores enfatizam a necessidade da antropologia enfrentar os pressupostos e paradig- 
mas políticos subjacentes ao seu projeto, mas ao mesmo tempo vêem nesse processo possibilidades novas para o futuro da disciplina. Clifford argumenta, na introdução a essa coletânea, que “o trabalho etnográfico tem-se definitivamente enredado em um mundo de desigualdades de poder duradouras e cambiantes, e continua implicado, sancionando relaçóes de poder. Mas sua função dentro dessas relaçóes é complexa, muitas vezes ambivalente e potencialmente contra-hegemônica" (Clifford 1986: 9).

Dado a implícita recusa de Trinh de ver nesses trabalhos um engajamento com os temas da sua crítica, a reação dos antropólogos tem sido muitas vezes de indignação no que concerne à sua representação do projeto antropológico. Henrietta Moore, por exemplo, escreve que:

Houve momentos, tanto em Reassemblage quanto em Naked Spaces [filme de Trinh de 1985], em que me senti em meio a um discurso antropológico antigo, do qual muitos antropólogos afirmam estar tentando escapar ao longo dos últimos vinte anos [...] a antropologia moderna, ao contrário, está muito mais preocupada em localizar culturas nos seus contextos históricos, realçar a natureza construída das identidades sociais e culturais, examinar a natureza conflitante e muitas vezes contraditória de valores sociais e auto-entendimentos, enfatizar as especificidades históricas e dimensóes de poder das representaçóes de "outras culturas" e, ao representar outras pessoas e a vida de outras pessoas, sublinhar a sua natureza cambiante, processual e dinâmica." (Moore 1994: 117)

Como devemos entender, então, a natureza da crítica de Trinh e a resposta que a mesma engendra em muitos antropólogos?

\section{Falar Perto}

Romper os sistemas existentes de valores dominantes e desafiar a própria fundação de uma ordem social e cultural não significa meramente destruir alguns preconceitos ou inverter as relaçóes de poder nos termos de uma economia do mesmo. Ao contrário, significa ver através da porta giratória de todas as racionalizaçóes e defrontar-se com a verdade daquela luta entre fiç̧óes.

(When the Moon Waxes Red, Trinh T. Minh-ha 1991: 6)

Em resposta à pergunta proposta acima, creio que a crítica de Trinh vai além dos deslocamentos do projeto antropológico provocados pelos pós-modernistas e os primeiros inovadores na área da antropologia visual. Assim sendo, a sua crítica se direciona tanto ao projeto pós-colonial da antropologia quanto à antropologia anterior. Na citação acima, Trinh argumenta que para realmente derrubar os sistemas de valores dominantes, é necessário efetuar um deslocamento profundo dos paradigmas hegemônicos da crítica e do entendimento, e não simplesmente reorganizar as fronteiras e relaçóes em um sistema duradouro de pensamento e poder. É isso, no fundo, que torna tão desafiante, desconcertante e, finalmente, tão difícil trabalhar com a proposta de Trinh, pois esse deslocamento implica uma avaliação de todas as referências e pressupostos que dão estrutura para o modo ocidental/intelectual/antropológico de pensar o mundo e a experiência humana. (Só para começar, verdade/ficção, ciência/arte, eu/outro, passado/presente e a própria distinção binária não nos servem mais ...) Submeterse à esse deslocamento deixa o/a antropólogo/a em terra insegura, pois, como pergunta Sarah Williams em um ensaio sobre críticas ao trabalho de Trinh, "se não aceitamos o direito modernista (e, ironicamente, também pós-modernista) de impor leituras autorais, como protegemos o privilégio acadêmico?” (1991: 2).

A dificuldade em saber como proceder com esse deslocamento pode assim explicar muitas das críticas ao trabalho de Trinh, 
que, em vez de tentar trabalhar com o desafio que este representa à disciplina, tendem a desprezá-lo como leitura simplista da prática etnográfica ou mais uma representação crítica que acaba caindo nas mesmas armadilhas discursivas que tenta superar (ver Moore 1994, Crawford 1992: 79 e Henley 1999: 42). Um desafio a mais do projeto de Trinh é que náo oferece nenhuma resposta "totalizante" para o que deve ser construído em lugar do discurso dominante que ela critica. De fato, parte dessa crítica é direcionada à própria noçáo da possibilidade da totalidade. "Ao desfazer modelos e códigos estabelecidos", argumenta Trinh,

a pluralidade não resulta em uma soma total. Ah menina, pegando água na beira da estradal por que despejar a luz dourada da lua? (Vietnamese Ca Dão). Essa não-totalidade estará sempre desconcertando ou despertando intolerâncias e ansiedades profundas (1991: 15).

Depois dos seus primeiros filmes, porém, Trinh acrescenta à sua crítica o desenvolvimento de algumas experiências num projeto alternativo de produção de conhecimento sobre a condição humana. E é aí que, se dotados de um olhar cuidadoso, poderemos ver, efetivamente, reflexos de correntes também em desenvolvimento na antropologia contemporânea, tanto dentro quanto fora do campo do visual. No cerne dessas correntes encontra-se uma crítica ao modo de produção de conhecimento clássico da antropologia ocidental no que tange à sua racionalidade cerebral, uma crítica em favor de uma aproximaçáo do mundo através da experiência corporal, individual e sensorial. Vemos isto, por exemplo, numa linha de pensamento no campo da antropologia da ciência e das novas tecnologias (especialmente na sua interface com a antropologia feminista), na sua crítica da distinção epistemológica entre natureza e cultura e da afirmação da objetividade científica, e na sua ênfase no corpo como lócus da produção do sentido. Donna Haraway, por exemplo, em um artigo intitulado "Saberes Localizados: a questão da ciência para o feminismo e o privilégio da perspectiva parcial", argumenta a favor de políticas e epistemologias de alocação, posicionamento e situação nas quais parcialidade e não universalidade é a condição de ser ouvido nas propostas a fazer de conhecimento racional. São propostas a respeito da vida das pessoas; a visão desde um corpo, sempre um corpo complexo, contraditório, estruturante e estruturado, versus a visão de cima, de lugar nenhum, do simplismo ([1988] 1995: 30). ${ }^{6}$

Outra linha de pensamento semelhante tem avançado bastante no campo da antropologia visual contemporânea, a ponto de alguns antropólogos verem no visual o meio por excelência da produção desse novo tipo de conhecimento. $\mathrm{O}$ próprio MacDougall argumenta

há recentemente um crescente interesse antropológico pela emoção, o tempo, o corpo, os sentidos, gênero e identidade individual [...] uma das dificuldades de se explorar e comunicar os entendimentos sobre essas questóes é a de encontrar uma linguagem que seja próxima a elas, tanto do ponto de vista metafórico quanto experimental. Uma das razóes que levou à primazia histórica do visual foi a sua capacidade de metáfora e sinestesia. Muito do que pode ser "dito" sobre essas questóes pode encontrar melhor expressão no meio visual (MacDougall 1997: 287).

Michael Taussig vai mais além, argumentando a favor de uma abordagem sensorial na produçáo de conhecimento em que o visual age como mero condutor para a experiência do sentido:

Benjamin pede que nós consideremos a arquitetura como um exemplo de conhecimento

6. Ver Latour 1999, para outra análise nessa direção, porém partindo mais especificamente da questáo do corpo. 
fisionômico habituado [...] que significa dizer que aqui opera uma tactilidade de visão indefinível [...] e apesar do fato do olho ser importante para sua canalização, essa tactilidade pode bem ser bem mais importante para nosso conhecimento da configuração especial, tanto nos seus aspectos físicos quanto sociais, do que a visão em algum sentido não-tátil do termo. É claro que o que acontece aqui é que o próprio conceito de "conhecer" algo fica deslocado por um "relacionar-se a." E o que é preocupante e empolgante é que não somente estamos estimulados a repensar o que quer dizer "visão" na medida em que esse termo se decompóe diante dos nossos olhos, mas também o fato de sermos forçados a nos perguntar por que a visão é tão privilegiada, em termos ideológicos, enquanto que outras modalidades sensoriais são, ao menos nas culturas euro-americanas, tão linguisticamente empobrecidas, apesar de cruciais, para o ser humano e à vida social. (1994: 209)

Através de um questionamento do privilegiado papel do visual na cultura européia/norte-americana em relação à outras 'modalidades sensoriais', Taussig critica, no texto acima, a possibilidade da produção de conhecimento no modo clássico ocidental ("o que acontece aqui é que o próprio conceito de 'conhecer' algo fica deslocado por um 'relacionar-se a'") de uma maneira que lembra o "falar perto" ("falar sobre") de Trinh. Em veio semelhante, o teórico de filme documentário Bill Nichols fala, na revista Visual Anthropology Review, da necessidade de se distanciar das "tentativas de falar de mente a mente, no discurso da sobriedade científica" e de coloca-se "na direção de uma política e epistemologia da experiência falada de corpo a corpo" (1994: 73).

Nesse meio, o trabalho de Trinh é recebido com mais seriedade por autores que se interessam por seu projeto e as suas implicaçóes para antropologia de modo mais geral. Nichols, por exemplo, reconhece que "Trinh T. Minh-ha oferece uma leitura sintomática e distanciada da prática antropológica desenhada para colocar seus pressupostos subjacentes em um estado de suspensão crítica” (1994: 72). Nichols reconhece que o gênero do filme etnográfico está precisando repensar seu projeto à luz de trabalhos de cineastas como Trinh, e que esses cineastas estão, na sua maioria, trabalhando fora das fronteiras disciplinares da antropologia. Porém, esse mesmo autor afirma a possibilidade do filme etnográfico enfrentar esses desafios, argumentando que "em lugar de descartar o filme etnográfico por deixar de atender a critérios (geralmente não-especificados) de validação antropológica baseados em uma concepção de antropologia como ciência e disciplina profissional, poderíamos ir adiante ... em direção a uma etnotopia que não abolirá a vivência, o corpo e o conhecimento que vem da barriga, mas que o afirmará" (1994: 69).

Sem dúvida, o fato de Trinh não ser antropóloga a permite desenvolver um projeto visual bastante radical sem se preocupar em associar a prática visual e a teoria antropológica, questáo esta que tem preocupado os antropólogos visuais desde Rouch e os MacDougall. Trinh subverte essa preocupação questionando a própria legitimidade de um tipo de produção de conhecimento que insiste em uma divisão entre esses dois aspectos. No trabalho de Trinh, o meio audiovisual permite a produção de um tipo diferente de conhecimento, que, de acordo com a sua crítica política e epistemológica, é explicitamente diferenciado das convençóes de produção de conhecimento da antropologia acadêmica ocidental. Ademais, ao rejeitar radicalmente esse mundo, Trinh consegue ir muito mais longe no desenvolvimento dessas novas possibilidades de produção de conhecimento do que muitos antropólogos, restritos em seu potencial de experimentação pelas limitaçóes da 'ordem social e cultural' em que 
sempre atuaram. Ou seja, ao se posicionar fora do mundo acadêmico ocidental (pelo menos ideologicamente), Trinh consegue oferecer a esse mundo experiências mais avançadas e radicais do que aquelas sendo lentamente desenvolvidas no seu próprio meio através de linhas de pensamento semelhantes.

\section{The Fourth Dimension: explorando a quarta dimensáo}

Partindo do teatro Kabuki do Japão pré-moderno, Eisenstein tornou mais complexa a teoria da montagem cinematográfica criando a noçáo de "harmônicos visuais" (visual overtone) originalmente estabelecida com a produção de $O$ Velho e o Novo em 1928. "A extraordinária qualidade fisiológica da dimensão emocional em $O$ Velho e o Novo, explicou o diretor, deve-se a esses harmônicos, uma "quarta dimensão filmica" que resulta em uma "sensação fisiológica."

(Physiognomic Aspects of Visual Worlds, Michael Taussig 1994: 210)

O penúltimo filme de Trinh, The Fourth Dimension (2001), é um sensível e enigmático exercício de falar perto. Tomando o Japáo como locus de reflexão, Trinh constrói uma viagem pessoal no tempo e no espaço através dos ritmos que emanam do ritual e do cotidiano. Como em seus outros filmes, Trinh não segue nenhuma regra do cinema convencional, e muito menos do filme etnográfico. The Fourth Dimension não tem história linear nem mensagem clara, e a rica e dinâmica trilha sonora é fragmentada, bem como as imagens e os comentários feitos pela própria Trinh, as únicas palavras faladas do filme, além de algumas falas curtas que não são traduzidas. A própria experiência de assistir o filme é perturbadora; percebe-se rapidamente que as convençóes e a ordem que "normalmente" estruturam um filme e conduzem o entendimento do seu conteúdo não vão servir aqui.
Assim sendo, exige que o espectador critique as suas reaçóes iniciais e se abra para uma experiência incerta de recepçáo que possibilita novos modos de entendimento e experiência. Será que, com isso, o espectador entra na "quarta dimensão" visual de Eisenstein? Certamente, é uma dimensáo sensorial em que imagem, som, memória, experiência pessoal (de Trinh e do próprio espectador) e reação corporal se encontram, desafiando e enriquecendo a tentativa do espectador de criar algum "sentido racional" - já que, no final das contas, fácil não é se livrar de dois séculos de discurso epistemológico em uma única tarde - a partir do que se está assistindo/ouvindo/sentindo.

The Fourth Dimension começa, literalmente, em uma neblina cinza, com a câmera em movimento numa estrada. Vagas formas de outros carros e placas de sinalização aparecem atrás da neblina, e temos a forte sensação de estarmos avançando em alguma direção, mas sem destino claro nem motivo. O primeiro comentário de Trinh, "Is it a fog? Or is it me?" (É uma neblina? Ou será que sou eu?) já aponta para certa impossibilidade de clareza/certeza tão típica dos comentários clássicos em filmes 'sobre outras culturas' e ao mesmo tempo localiza Trinh, como self, no âmbito do filme. Uma citação logo aparece escrita na tela, "coração da viajante nunca permaneceu muito tempo em um só lugar como um fogo portátil - Basho", e a sensação de estar acompanhando uma viagem aumenta.

A viagem de Trinh, porém, é condição para se explorar a experiência de estar fora de um lugar, de uma "cultura", ao mesmo tempo em que se está perto e presente. Falar perto do Japão, nessa condiçãa, torna-se oportunidade de sentir, experimentar, refletir, sem precisar ou procurar "explicar" o que aparece na frente da câmera. E é nesse caminho que a "outra dimensão" aparece para subverter a solidez e a certeza da "percepção normal". Trinh comenta em off, 
acompanhada por uma série de imagens de pedras trabalhadas num jardim arborizado (um cemitério? um monumento sagrado?):

aquilo que vemos se vai/ aquilo que é mais evidente passa para o segundo plano/ enquanto os detalhes menores continuam alterando aquilo que é visto e ouvido/ a outra dimensão/ gasoso e líquido/ porque o que parece evidente ao olho é uma linha reta/ a percepção normal é sólida, geométrica, bem-definida e divisora

O filme apresenta inúmeras imagens e comentários, refletindo (entre outras) as questóes de tempo, tradição, modernidade, velocidade, espaço e arquitetura; mas, o tema que parece dominar o filme é o do ritual. Em planos de diversos rituais musicais e performativos filmados no Japáo urbano e rural, Trinh explora a experiência sensorial do comportamento humano coletivo. Esse tema, porém, é subvertido por Trinh de duas maneiras. Primeiro, ao mostrar o ritualismo da atividade cotidiana em várias cenas rítmicas, como as de uma academia de ginástica e outras dentro do trem urbano, onde ressalta a experiência erótico-sensorial do corpo e máquina juntos, em movimento. Segundo, ao enfocar repetidamente nos rostos dos participantes dos rituais em plano fechado, e nos vários planos dos participantes em momentos de descanso no começo, meio ou fim dos rituais performáticos, momentos estes liminares, em que os participantes, ainda vestidos nos figurinos 'tradicionais' dos rituais, batem papo e adotam posturas corporais relaxadas que contrastam com a rígida coletividade das performances de alguns minutos antes ou depois. Trinh comenta: "é somente quando o comportamento cuidadosamente ensaiado se torna coletivo que as diferenças realmente assumem suas cores individuais".

Nesta subversão à questão - tão cara à antropologia - da interface entre o coletivo e o individual, vemos Trinh desafiando, mais uma vez, as categorias que sublinham e dão forma à nossa disciplina. Como já vimos acima, muitos dentro das fronteiras acadêmicas da antropologia já se preocupam em fazê-lo (existe, é claro, uma literatura contemporânea maciça sobre a questão indivíduo-sociedade que não cabe explorar aqui), mas o que é tão interessante no trabalho de Trinh é que aquilo que oferece em lugar do que critica não é um refazer do mesmo, mas algo radicalmente diferente, possibilitado por sua apropriação do meio visual. Muitas vezes, o resultado dessa experiência nos confunde, incomodando nossos olhos, ouvidos e sentidos intelectuais, bem como os tons agudos tão característicos das trilhas sonoras dos seus filmes. Mas é exatamente isso que precisamos enfrentar: novos modos de conhecimento com os quais talvez não estejamos acostumados, que não entendemos e com os quais não sabemos, de primeira, dialogar, elogiar ou criticar. Aqui encontramo-nos novamente diante do desafio que está atualmente abalando a antropologia. Temos que aceitar a possibilidade de outras maneiras de conhecer o mundo, maneiras que não cabem sempre em nossos próprios enquadramentos e estruturas intelectuais, e procurar modos de falar (perto) delas mesmo assim.

Com isso, precisamos também enfrentar outro desafio colocado por Trinh: a impossibilidade de chegar a 'conclusóes', de reivindicar a nossos trabalhos a condição de totalidade e fechamento. A última frase de The Fourth Dimension, que aparece escrita na tela superposta à imagem de uma flor de lótus, é:

O mundo inteiro é a nossa mente, a mente de uma flor.

(Dogen Zenyi)

$\mathrm{Na}$ sua crítica da busca da verdade dominante, qualquer e de quem quer que seja, o trabalho de Trinh abraça a multiplicidade da 
experiência humana e das infinitas perspectivas localizadas na mente - e no corpo - de cada um. A mente aqui não é uma mente totalizante e singular, mas a mente de uma flor, abrindo-se para incorporar os vários selves de um corpo e suas várias experiências do mundo. Desta forma, ao mesmo tempo em que Trinh subverte a possibilidade de conclusóes, seu trabalho pede um mundo acadêmico em que a ausência dessas últimas não implica em uma falha da/do acadêmica/o em provar sua competência, mas na possibilidade de se colocar nesse mundo falando perto das suas experiências e das experiências que observa no seu entorno. Assim sendo, não ofereço nenhuma conclusão fechada a esse ensaio. Ao contrário, procuro abrir, com ele, mais uma flor no mundo.

\section{The fourth dimension in the work of Trinh T. Minh-ha: challenges for the an- thropology or learning to talk close}

abstract The work of filmmaker and feminist, post-colonial theorist Trinh T. Minh-ha is considered here in terms of the challenges it poses for both visual anthropology and the discipline's project on a wider scale. Trinh's work reflects developing trends in anthropology - especially in the realm of the visual - in relation to both post-colonial critique and the growing interest in new methods for the production of knowledge about the world which reject the cerebral rationality of older Western anthropological theory in favor of more corporal, individual and sensorial means of understanding human experience. However, I argue that the radical nature of Trinh's critique and her position outside of the confines of academic anthropology result in advances in this direction in her work that go beyond the limited attempts in the same vein currently in development within the discipline. In this article I explore this interface between Trinh's work and such trends in contemporary visual anthropology before looking more closely at the outcome of her experimental practice in one particular work, The Fourth Dimension, Trinh's penultimate film produced in 2001.

keywords Visual anthropology. Post-colonial critique. Experimental film.

\section{Referências bibliográficas}

CLIFFORD, James. 1986. "Introduction: Partial Truths". In J. Clifford e G. E. Marcus (orgs.), Writing Culture: The Poetics and Politics of Ethnography. Berkeley e Los Angeles: University of California Press, pp. 1-26.

CRAWFORD, Peter Ian. 1992. "Film as discourse: the invention of anthropological realities". In P. I. Crawford e D. Turton (orgs.), Film as Ethnography. Manchester: Manchester University Press, pp.66-82.

GRIMSHAW, Anna. 2001. The Ethnographer's Eye: Ways of Seeing in Modern Anthropology. Cambridge: Cambridge University Press.

HARAWAY, Donna. 1995. "Saberes Localizados: a questáo da ciência para o feminismo e o privilégio da perspectiva parcial". Cadernos Pagu, (5): 07-41.

HEIDER, Karl G. 1976. Ethnographic Film. Austin: University of Texas Press.

HENLEY, Paul. 1999. "Cinematografia e pesquisa etnográfica". Cadernos de Antropologia e Imagem, 9(2): 29-50.

LATOUR, Bruno. 1999. "How to talk about the body? The normative dimension of science studies". Paper apresentado no simposio 'Theorizing the Body', Paris, França.

MACDOUGALL, David. 1997. "The Visual in Anthropology”. In M. Banks, H. Morphy (orgs.), Rethinking visual Anthropology. New Haven/London: Yale University Press, pp. 276-295.

MEAD, Margaret. [1975]. "Visual Anthropology in a Discipline of Words". In P. Hockings (org.), Principles of Visual Anthropology. New York: Mouton de Gruyter, pp. 3-10, 1975.

MOORE, Henrietta L. 1994. "Trinh T. Minh-ha Observed: Anthropology and Others". In L. Taylor (org.), $V i$ sualizing Theory. Selected Essays from V.A.R. 1990-1994. New York and London: Routledge, pp. 115-125.

NICHOLS, Bill. 1994. "The Ethnographer's Tale". In L. Taylor (org.), Visualizing Theory. Selected Essays from V.A.R. 1990-1994. New York and London: Routledge, pp. 60-83. 
PRATT, Mary Louise. 1986. "Fieldwork in Common Places". In J. Clifford e G. E. Marcus (orgs.), Writing Culture: The Poetics and Politics of Ethnography. Berkeley e Los Angeles: University of California Press, pp. 27-50.

ROSALDO, Renato. 1986. "From the Door of His Tent: The Fieldworker and the Inquisitor". In J. Clifford e G. Marcus (orgs.), Writing Culture: The Poetics and Politics of Ethnography. Berkeley e Los Angeles: University of California Press, pp. 77-97.

SAHLINS, Marshall. [1993]. Esperando Foucault, ainda. São Paulo: Cosac Naify, 2004

SZTUTMAN, Renato. 2004. "Jean-Rouch: Um Antropólogo-cineasta”. In S. C. Novaes, [et al.] (orgs.), Escrituras da Imagem. Sáo Paulo: Fapesp / Editora da Universidade de São Paulo, pp. 49-62.
TAUSSIG, Michael. 1994. "Physiognomic Aspects of Visual Worlds”. In L. Taylor (org.), Visualizing Theory. Selected Essays from V.A.R. 1990-1994. New York and London: Routledge, pp. 205-213.

TRINH, T. Minh-ha. 1991. When the Moon Waxes Red. New York and London: Routledge.

WILLIAMS, Sarah. 1991. "Suspending Anthropology's Inscription: Observing Trinh Minh-ha Observed". Visual Anthropology Review, 7 (1):7-14.

\section{Filmografia}

The Fourth Dimension. Direção: Trinh T. Minh-há. Japão / Estados Unidos, 2001. (87 min.)

Reassemblage. Direção: Trinh T. Minh-há. Senegal / Estados Unidos, 1982. (40 min.)

\section{autor Jessie Sklair \\ Mestranda em Antropologia Social / USP}

Recebido em 24/02/2006

Aceito para publicação em 18/05/2006 